\title{
Video-assisted thoracic surgery (VATS) non-grasping en bloc mediastinal lymph node dissection for the left side
}

\author{
Lin Ma, Chengwu Liu, Jiandong Mei, Yanbo Yang, Lunxu Liu \\ Department of Thoracic Surgery, West China Hospital, Sichuan University, Chengdu 610041, China \\ Correspondence to: Lunxu Liu, MD, PhD. Department of Thoracic Surgery, West China Hospital, Sichuan University, No. 37, Guoxue Alley, \\ Chengdu 610041, China. Email: lunxu_liu@aliyun.com.
}

Submitted Oct 10, 2018. Accepted for publication Oct 22, 2018.

doi: $10.21037 /$ jtd.2018.10.101

View this article at: http://dx.doi.org/10.21037/jtd.2018.10.101

\section{Introduction}

One major obstacle to the acceptance of the thoracoscopic approach of lung cancer surgery is the uncertainty as to whether the extent and quality of mediastinal lymph node dissection (MLND) are equal to those of thoracotomy. The main issue is that the lymph nodes (LNs) locate deep in the mediastinal space and surrounded by large vessels, bronchi, esophagus and heart. Several methods have been reported to solve this problem, such as using a novel retractor or via anterior subcarinal approach $(1,2)$. This video depicts a left side thoracoscopic MLND following en bloc strategy and non-grasping strategy, which dissect each node station block along the defined surgical anatomic landmarks with endoscopic suction (ES) and energy devices as the main equipment, named as "non-grasping en bloc MLND" (Figure 1).

\section{Operative techniques}

Anesthesia, position of patient, port design, and anatomical lobectomy are performed according to the "single-direction" strategy which is outlined in our previous description (4). Lymphadenectomy is performed after lobectomy. As recommended, we routinely dissect stations $4,5,6,7,8$, and 9 for the left-side MLND. Three main instruments are used: ES, cautery hook (CH) and ultrasonic scalpel (US). During a left-side procedure the ES is inserted through the main utility incision while the $\mathrm{CH}$ or US is inserted through the assistant utility incision. The LNs and the surrounding fat tissue which located among the anatomic landmarks of each LN station are dissected en bloc. In this video, we focus on describing a left side MLND involving stations 4, 5, 6 and 7 .

\section{$5 L$}

After retraction of the remnant lung posterior to the left costophrenic corner, the mediastinal pleura is opened along the triangular area delimited by the phrenic nerve, the vagus nerve, and the superior border of the left main pulmonary artery. Firstly, the station 5 block is separated from the vagus nerve by the $\mathrm{CH}$ and pushed anterior to the phrenic nerve by the ES. It is then dissected off by the US from the aortopulmonary window and ended at the phrenic nerve.

\section{$6 L$}

The station 6 block is located between the phrenic nerve and the thymus by the side of the ascending aorta. The key step is retraction of the LNs and fat tissue beneath the phrenic nerve anterior to the thymus using the ES. The block is then dissected using the US at the level of the left main pulmonary artery to the top of the arcus aortae, and shoveled en bloc. During the operation, the surgeon must keep in mind not to injure the phrenic nerve.

\section{$4 L$}

After retraction of the remnant lung anterior to the cardiophrenic angle, the mediastinal pleura between the ligamentum arteriosum, left main pulmonary artery, vagus nerve, and left main bronchus is opened by the $\mathrm{CH}$. After transecting the bronchial arteries and branch of the vagus nerve to the lung, the block is pressed downward by the 


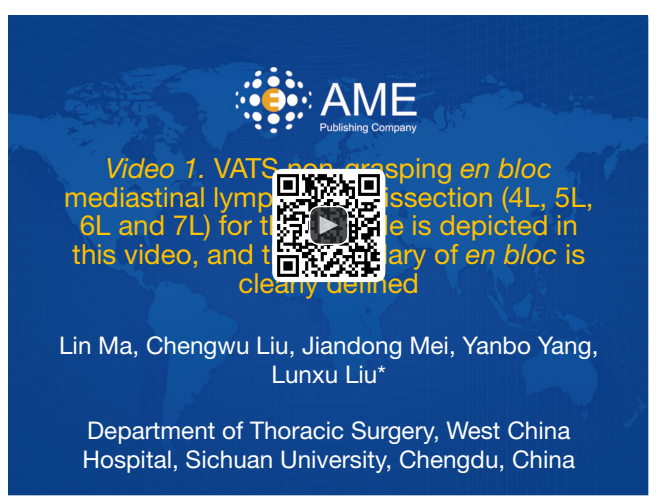

Figure 1 VATS non-grasping en bloc mediastinal lymph node dissection $(4 \mathrm{~L}, 5 \mathrm{~L}, 6 \mathrm{~L}$ and $7 \mathrm{~L}$ ) for the left side is depicted in this video, and the boundary of en bloc is clearly defined (3). VATS, video-assisted thoracic surgery; LNs, lymph nodes; PA, pulmonary artery; AA, ascending aorta; DA, descending aorta; $\mathrm{RMB}$, right main bronchus; LMB, left main bronchus; PV, pulmonary vein. Available online: http://www.asvide.com/article/view/28464

$\mathrm{ES}$, and blunt dissection is performed by the US to expose the recurrent laryngeal nerve. Skeletonization of the nerve is not necessary. After this, the block is dissociated from the inferior border of the aortic arch along the recurrent laryngeal nerve. Finally, the block is hollowed out from the interspace among the aortic arch, top of the left main pulmonary artery, the ligamentum arteriosum and the left main bronchia, and deep to the lower portion of the trachea. The left recurrent laryngeal nerve must be identified and meticulously protected.

\section{$7 L$}

After retraction of the remnant lung anterior to the cardiophrenic corner, the mediastinal pleura between the left main-stem bronchus and esophagus is opened. Similar to the procedure performed on the right side, the station 7 block is first separated from the esophagus until the right main bronchus is revealed and the carina can be identified. Simultaneously, the bronchial arteries and branches of the vagus nerve to the lung are transected by the $\mathrm{CH}$. Then, the ES is used as a spatula to press the block along with the left atrium. Dissection starts from the distal part of the right main bronchus by the US. After LN-lysis from the right main bronchus, the block is lifted away from the pericardium by the ES and separated from it by the US. Finally, the station 7 block is dissected off the left main bronchus and carina after ligation of the subcarinal bronchial artery by the US. The en bloc dissection is then complete.

\section{Comments}

In the guidelines of the National Comprehensive Cancer Network (NCCN) for non-small-cell lung cancer, the location of the mediastinal lymph nodes is only roughly depicted; however, the en bloc lymphadenectomy requires an accurate surgical border to follow. In our technique, the surgical anatomic boundary of en bloc dissection is clearly defined and is used to instruct our surgical procedure. We zone the main mediastinal LNs into 4 blocks on the left side: station 4, station 5, station 6 and station 7. The boundaries of the surgical anatomic landmark of the station 4 block are defined by the following: the cephalic border is the aortic arch, the caudal border is the top of the left main pulmonary artery and the initial part of the left main bronchus, the anterior border is the ligamentum arteriosum, the posterior border is the descending aorta and esophagus, and the right border is the lower portion of the trachea. The boundary of the station 5 block is a triangular area delimited by the phrenic nerve (anterior border), the vagus nerve (posterior border), and the superior border of the left main pulmonary artery (caudal border). The station 6 block is located in the area surrounded by the left side of the thymus (anterior border), the phrenic nerve (posterior border), and the superior border of the left main pulmonary artery (caudal border). The definition of boundaries of the station 7 block are the following: the cephalic border is the left and right main bronchus (above the level of the bilateral lower lobes) and carina, the caudal border is the superior border of the inferior pulmonary vein, the anterior border is the pericardium, and the posterior end point is the esophagus and the descending aorta.

Before the dissection of the station 4 block, the recurrent laryngeal nerve must be first identified. As undue retraction and thermal injury should be avoided, a blunt dissection is recommended. When hollowing out the block, the left pulmonary artery should be protected under the ES. During the dissection of the station 5 block, the phrenic nerve and the vagus nerve should be identified and the nerves should not to be skeletonized. Dissection of the station 7 block from the left side is more difficult than the right side, because the LNs are covered by the aorta and esophagus. Separating the block from the esophagus and ligating the bronchial artery between them can reduce the blood supply to the LNs and facilitate the next dissection. Using the 
ES to press the left atrium appropriately can reduce the influence caused by the beating heart and gain sufficient working space. The lysis of the block from the pericardium turns the station 7 block into a flaky structure which can be more easily shoveled off from the right and left main bronchus.

\section{Acknowledgements}

None.

\section{Footnote}

Conflicts of Interest: The authors have no conflicts of interest to declare.

Informed Consent: Written informed consent was obtained from the patient for publication of this manuscript and any

Cite this article as: Ma L, Liu C, Mei J, Yang Y, Liu L. Video-assisted thoracic surgery (VATS) non-grasping en bloc mediastinal lymph node dissection for the left side. J Thorac Dis 2018;10(11):6271-6273. doi: 10.21037/jtd.2018.10.101 accompanying images.

\section{References}

1. Sato Y, Tezuka Y, Kanai Y, et al. Novel retractor for lymph node dissection by video-assisted thoracic surgery. Ann Thorac Surg 2008;86:1036-7.

2. Baste JM, Haddad L, Melki J, et al Anterior subcarinal node dissection on the left side using video thoracoscopy: an easier technique. Ann Thorac Surg 2015;99:e99-e101.

3. Ma L, Liu C, Mei J, et al. VATS non-grasping en bloc mediastinal lymph node dissection $(4 \mathrm{~L}, 5 \mathrm{~L}, 6 \mathrm{~L}$ and $7 \mathrm{~L})$ for the left side is depicted in this video, and the boundary of en bloc is clearly defined. Asvide 2018;5:867. Available online: http://www.asvide.com/article/view/28464

4. Liu L, Che G, Pu Q, et al. A new concept of endoscopic lung cancer resection: Single-direction thoracoscopic lobectomy. Surg Oncol 2010;19:e71-7. 